\title{
Gross calorific and ash content assessment of recycled sawdust from mushroom cultivation using near infrared spectroscopy
}

\author{
Jetsada Posom $^{1,3}$, Jirawat phuphanutada ${ }^{2,4}$, and Ravipat Lapcharoensuk ${ }^{2,4^{*}}$ \\ ${ }^{1}$ Department of Agricultural Engineering, Faculty of Engineering, Khon Kaen University, Khon Kaen, Thailand \\ ${ }^{2}$ Department of Agricultural Engineering, Faculty of Engineering, King Mongkut's Institute of Technology Ladkrabang, Bangkok, \\ Thailand \\ ${ }^{3}$ Applied Engineering for Important Crops of the North East Research Group, Department of Agricultural Engineering, Faculty of \\ Engineering, Khon Kaen University 40002, Thailand \\ ${ }^{4}$ Post Harvest Innovation Research and Development Laboratory, Department of Agricultural Engineering, Faculty of Engineering, King \\ Mongkut's Institute of Technology Ladkrabang, Bangkok, Thailand
}

\begin{abstract}
The aim of this study was to use the near infrared spectroscopy for predicting the gross calorific value (GCV) and ash content (AC) of recycled sawdust from mushroom cultivation. The wavenumber was in range of 12500-4000 $\mathrm{cm}^{-1}$ with the diffuse reflection mode was used. The NIR models was established using partial least square regression (PLSR) and was validated via using full cross validation. GCV model provided the coefficient of determination $\left(\mathrm{R}^{2}\right)$, root mean square error of cross validation (RMSECV), ratio of prediction to deviation (RPD), and bias of $0.90,445 \mathrm{~J} / \mathrm{g}, 3.19$ and $4 \mathrm{~J} / \mathrm{g}$, respectively. The AC model gave the $\mathrm{R}^{2}$, RMSECV, RPD and bias of $0.83,1.7000 \% \mathrm{wt}, 2.44$ and $0.0059 \% \mathrm{wt}$, respectively. For prediction of unknow samples, GCV model provided the standard error of prediction (SEP) and bias of $670 \mathrm{~J} / \mathrm{g}$ and -654 $\mathrm{J} / \mathrm{g}$, respectively. The AC model gave the SEP and bias of $1.84 \% \mathrm{wt}$ and $0.912 \% \mathrm{wt}$, respectively. The result represented that the GCV and AC model probably used as the rapid method and non-destructive method.
\end{abstract}

\section{Introduction}

Mushroom, one of the most popular and a valuable edible fungus is highly appreciated in human diet because of its delicacy, texture and extreme amounts of proteins, minerals and bioactive compounds [1]. In Thailand, many cultivated mushrooms are well-established consumer acceptance such as Auricularia spp., Volvariella volvacea, Pleurotus sajor-caju [2-4]. Para rubber tree (Hevea brasiliensis) sawdust are used for mushroom cultivation popularly in Thailand due to the rubber tree sawdust is large waste from the local furniture industry [5]. Most of the time, the sawdust after mushroom cultivation is often reused to fertilizer, and it is either piled up in fields for a slow degradation. The recycle of these agricultural waste materials may help to improve the regional economies of the country.

Biomass are forms of renewable energy directly derived from organic materials such as plants, fastgrowing trees and agricultural residues and waste. The most important characteristic of biomass is used to design planning and operation of thermal power plant is the energy content (heating value). The heating value defines how biomass is used to achieve process efficiency. Heating value can be divided into higher heating value (HHV) or gross calorific value (GCV); and lower heating value (LHV) or net calorific value (NHV). The bomb calorimeter is instrument for determination of the GCV.
Ash (A) content is one of the largest problems of Biomass combustion. In combustion process, AC often called slagging and fouling deposit. These problems have negative impacts on the boiler, such as reducing the heat exchange and boiler efficiency [6]. The AC has a negative effect on the GCV, increasing $1 \%$ in $\mathrm{A}$ of wood fuels decrease a $0.2 \mathrm{MJ} \mathrm{kg}^{-1}$ in its GCV [7-8]. Nowadays, the $\mathrm{AC}$ can determine with dry ashing method. However, both standard methods for the determination of GCV and A require long analysis times and highly skilled technicians, and they are destructive to samples. Consequently, a novel analytical method that is fast, easy and non-destructive for evaluating GCV and AC of recycled sawdust is highly sought after within biomass processing.

Near infrared spectroscopy (NIRs) have been used to evaluate properties of biomass in many researches. GCV of various biomass was successfully predicted using NIRs such as millet [9], leucaena leucocephala [10], jatropha curcas kernels [11], and straw [12]. In addition, Fagen et al. [13] studied application of NIRs for measuring moisture content, gross calorific value (GCV), carbon (C) and ash content (AC) of two dedicated bioenergy crops which results of their showed performance of NIRs technique to evaluate these properties. Therefore, the NIRs is interesting technique to apply for GCV of recycled sawdust evaluation. The aim of this study was to the use of near infrared spectroscopy for predicting the

\footnotetext{
* Corresponding author: ravipat.la@kmitl.ac.th
} 
GCV and AC of recycled sawdust from mushroom cultivation.

\section{Material and method}

\subsection{Sample preparation}

The recycled sawdust samples obtained from mushroom cultivation of 3 breeds which are Indian oyster (Pleurotus pulmonarius), Bhutan oyster (Pleurotus pulmonarius) and Poplar (Agrocybe aegerita). All samples were sawdust of Para rubber tree. The samples were collected from 16 mushroom farms in Nakhon Pratom province. Two samples were kept on each farm. Therefore 32 samples were for calibration set. These samples were used for modelling. After modelling, 10 samples of recycled sawdust were collected from Ratburi district which were defined to external validation set (unknow samples). Hence the total sample equal to 42 samples (32 for calibration set and 10 samples for external validation set). All samples were dried by a hot air oven (Memmert, model ULM 500, Germany) at $105^{\circ} \mathrm{C}$ until got constant weight. After that, it was kept at the room temperature for 5 days to balance relative humidity and kept in aluminium bag for experiment.

\subsection{NIR spectra scanning}

Each sample was poured into sample cup, dimension was $35 \mathrm{~mm}$ of height and 50 of diameters. The samples were scanned using Fourier-Transform Near Infrared spectrometer (Bruker Ltd., Germany). The scanning condition was: diffuse reflectance mode, wavenumber range between $12500-4000 \mathrm{~cm}^{-1}(800-2500 \mathrm{~nm}), 32$ scans per sample with a resolution of $8 \mathrm{~cm}^{-1}$, at room temperature of $25 \pm 2{ }^{\circ} \mathrm{C}$, and absorbance of $\log 1 / \mathrm{R}$ unit where $\mathrm{R}$ is reflection of NIR radian from the sample. The sample at the bottom of the cup, it was irradiated by NIR radiation, was obtained to determine the reference data i.e. GCV and AC since it contained more NIR spectral information. It was kept in plastic bag for experiment.

\subsection{Gross calorific and ash content analysis}

After scanning, about $0.5 \pm 0.1 \mathrm{~g}$ sawdust sample was compressed into pellet which used to determine GCV and carried on by bomb calorimeter (c200, IKA, Germany). Each sample was done duplicate and averaged to be one. After burning, AC was calculated by

$$
\operatorname{Ash}(\% w t)=\frac{w_{a}}{w_{s}} \times 100
$$

where $\mathrm{w}_{\mathrm{a}}$ is weight of solid residue after burning $(\mathrm{g})$ and $\mathrm{W}_{\mathrm{s}}$ is weight of sample before burning $(\mathrm{g})$.

\subsection{Repeatability and maximum $\left(R_{\max }^{2}\right)$}

Accuracy of reference method was determined as repeatability (Rep). Rep is the standard deviation between duplicate, it is the error obtained from man, machine, and method. Rep was also applied to calculate the maximum coefficient of determination $\left(\mathrm{R}_{\max }^{2}\right)$, it was calculated as followed Dardenne [14].

$$
\mathrm{R}_{\max }^{2}=\frac{\mathrm{SD}_{\mathrm{y}}^{2}-\mathrm{Rep}^{2}}{\mathrm{SD}_{\mathrm{y}}^{2}}
$$

$\mathrm{SD}_{\mathrm{y}}$ is standard deviation of reference data. As seen the equation, $\mathrm{R}_{\max }^{2}$ is high when either high $\mathrm{SD}_{\mathrm{y}}$ or low Rep. The $\mathrm{R}^{2}$ will be highest if there is no spectral error [14].

\subsection{NIR spectroscopy modelling}

The total samples of 32 were used for model development. The PLS technique was used as mathematical algorithm and validated by full cross validation. The NIR spectra either non-preprocessed or preprocessed were applied. The following preprocessing technique were constant offset elimination, $1^{\text {st }}$ derivative, $2^{\text {nd }}$ derivative, multiplicative scatter correction (MSC) and standard normal variate (SNV), and scatter plot of regression coefficient and X-loading weight was represented. The performance of calibration model was then stated by statistical terms of coefficient of determination of calibration set $\left(\mathrm{R}^{2}\right)$ and validation set $\left(\mathrm{r}^{2}\right)$, root mean square error of estimation (RMSEE), root mean square error of cross validation (RMSECV), ratio of prediction to deviation (RPD) and bias. After model development, to ensure that whether model can predict the further sample. NIR spectroscopy models was tested again by the 10 samples of external validation set or unknow samples. The NIR spectroscopy models were performed using the multivariate statistical software of OPUS software V. 7.0.129 (Bruker Optik GmbH, German).

\section{Results and discussion}

\subsection{GCV and ash content of sawdust}

Fig. 1 displayed the relationship between GCV and AC of recycled sawdust, the GCV decreased with increasing AC. The coefficient of determination $\left(\mathrm{R}^{2}\right)$ equals to 0.785 , the linear equation was:

$$
\mathrm{Y}=-0.0027 \mathrm{X}+50.102
$$

when $\mathrm{X}$ is $\mathrm{AC}(\% \mathrm{wt})$ and $\mathrm{Y}$ is $\operatorname{GCV}(\mathrm{J} / \mathrm{g})$.

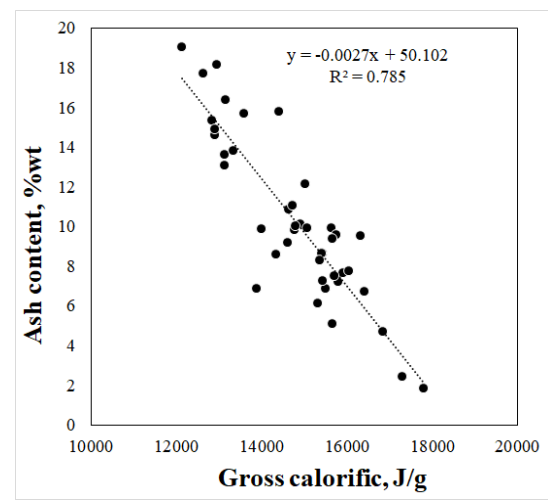

Fig. 1. The relationship between gross calorific and ash content of sawdust. 
Table 1 demonstrated the statistical data i.e. maximum, minimum, mean, and standard deviation (SD) for calibration set and external validation set. The GCV and $\mathrm{AC}$ were between 12119-17777 J/g and 1.866-19.034 $\%$ wt, respectively.

Table 1. Statistical data used for model development and external validation set.

\begin{tabular}{llllll}
\hline Data set & Parameters & Max & Min & Mean & SD \\
\hline Calibration & GCV $(\mathrm{J} / \mathrm{g})$ & 17777 & 12119 & 14590 & 1453 \\
& $\mathrm{AC}(\% \mathrm{wt})$ & 19.034 & 1.866 & 10.619 & 4.297 \\
External & $\mathrm{GCV}(\mathrm{J} / \mathrm{g})$ & 17282 & 14383 & 15353 & 867 \\
validation & $\mathrm{AC}(\% \mathrm{wt})$ & 15.815 & 2.459 & 9.224 & 3.669 \\
\hline
\end{tabular}

Repeatability and $\mathrm{R}_{\max }^{2}$ including calibration set and unknown sample were illustrated in Table 2. It was found that the capacity of NIR spectroscopy can give the $\mathrm{R}_{\max }^{2}$ of 0.98 and 0.90 for GCV and AC, respectively.

Table 2. Repeatability and maximum coefficient of determination $\left(\mathrm{R}_{\max }^{2}\right)$

\begin{tabular}{lll}
\hline Parameters & Repeatability & $\mathrm{R}_{\max }^{2}$ \\
\hline $\mathrm{GCV}(\mathrm{J} / \mathrm{g})$ & 155 & 0.98 \\
$\mathrm{AC}(\% \mathrm{wt})$ & 1.273 & 0.90 \\
\hline
\end{tabular}

\subsection{NIR spectra of sawdust sample}

Fig. 2 demonstrated raw spectra of sawdust. The NIR spectra of sawdust show obvious absorption peaks at wave band for $5188 \mathrm{~cm}^{-1}(1928 \mathrm{~nm}), 4779 \mathrm{~cm}^{-1}$ (2092 nm) and $4409 \mathrm{~cm}^{-1}(2268 \mathrm{~nm})$, they related to $\mathrm{O}-\mathrm{H}$ stretching and $\mathrm{HOH}$ combination of water [15]; $2 \times \mathrm{O}-\mathrm{H}$ deformation $+2 \times \mathrm{C}-\mathrm{O}$ stretching of starch [16]; and lignin [15].

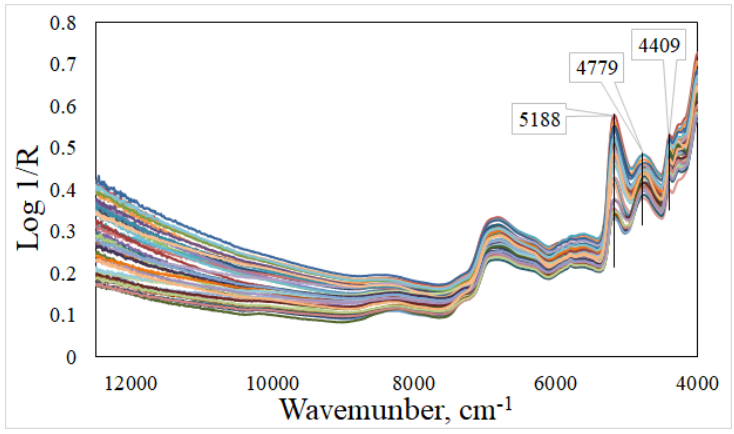

Fig. 2. NIR spectra of sawdust samples.

\subsection{NIR spectroscopy modelling}

Table 3 gave the result of PLS model predicted the GCV and $\mathrm{AC}$. The optimal model for GCV was generated by wavenumber range of 7502.2-4597.7 $\mathrm{cm}^{-1}$, using the preprocessing method of $1^{\text {st }}$ derivative + MSC, and PLS factor of 7, the $\mathrm{r}^{2}$, RMSECV, RPD and bias were 0.90, 445 $\mathrm{J} / \mathrm{g}, 3.19$, and $4 \mathrm{~J} / \mathrm{g}$, respectively. Meanwhile, AC model was developed using wavenumber range of 6102-5446.3 $\mathrm{cm}^{-1}$ without preprocessing, and PLS factor of $5, \mathrm{r}^{2}$, RMSECV, RPD and bias were 0.83, $1.7 \% \mathrm{wt}, 2.44$ and $0.006 \% w t$, respectively. $\mathrm{r}^{2}$ and RPD were recommended by Williams [17], $\mathrm{r}^{2}$ was $0.83-0.90$, the model could be used with caution for most application, and 0.66-0.81 could be used for screening and approximating, meanwhile, RPD between 3.1-4.9 used for any application and 2.4-3.0 for rough screening. Hence the GCV model could be used with caution for most application while AC model could be used for screening and approximating. However, the ratio between bias and its mean were approximately $0.025 \%(4 \mathrm{~J} / \mathrm{g}$ to $14590 \mathrm{~J} / \mathrm{g}$ ) for $\mathrm{GCV}$ model and $0.055 \%(0.006 \%$ wt to $10.619 \% \mathrm{wt})$ for $\mathrm{AC}$ model, their error was very small. Hence, the author recommended that it was acceptable for screening. Fig. 3 represents scatter plot between calibration set and validation set by full cross value validation of GCV and AC, respectively.
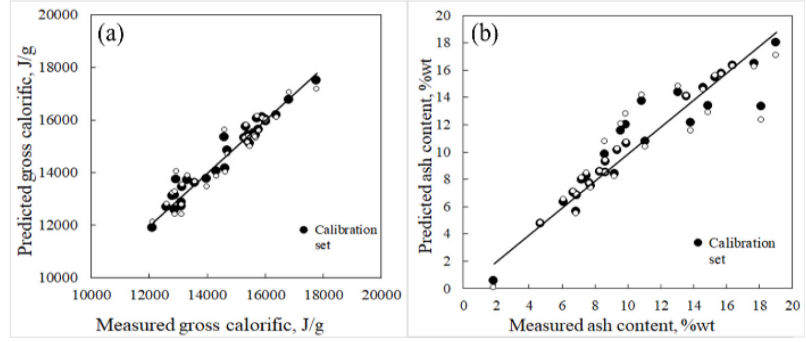

Fig. 3. Scatter plot between actual value and predicted value of a) gross calorific value and b) ash content both of calibration and validation set.

Fig. $4 \mathrm{a}$ and $4 \mathrm{~b}$ showed the regression coefficient plot and X-loading of GCV model. The obvious peaks were at around 5419-4597 $\mathrm{cm}^{-1}(1845-2175 \mathrm{~nm})$, related to starch (1960 and $2100 \mathrm{~nm})$, C-O stretch combination $(2100 \mathrm{~nm})$; asym $\mathrm{C}-\mathrm{H}$ stretch/C-H deformation combination of $\mathrm{HC}=\mathrm{CH}(2170 \mathrm{~nm})[18]$. As we know, $\mathrm{AC}$ is the inorganic material, there is no interaction with NIR radian. Author opinions that NIR spectroscopy can predict AC because the inner relationship between $\mathrm{AC}$ and $\mathrm{GCV}$ was used to generate with mathematical algorithm. Fig. $4 \mathrm{c}$ and $4 \mathrm{~d}$ illustrated the regression coefficient plot and X-loading of AC model. The wavenumber range between 6102-5402 $\mathrm{cm}^{-1}(1638-1851 \mathrm{~nm})$ was optimal, this band covers the vibration band of aromatic $(1685 \mathrm{~nm}), \mathrm{CH}_{3}(1695 \mathrm{~nm}$ and $1705 \mathrm{~nm}$ ), $\mathrm{CH}_{2}$ (1725 and $1765 \mathrm{~nm}$ ), cellulose (17810 and $1820 \mathrm{~nm})$, and water $(1790 \mathrm{~nm})$ [18]. The regression coefficient plot and X-loading of any wavenumber is high, means its vibrational band strongly effect to the prediction of predicted value.

Table 3 Result of PLS model for predicting gross calorific and ash content.

\begin{tabular}{|c|c|c|c|c|c|c|c|c|c|}
\hline \multirow[t]{2}{*}{ Parameters } & \multirow[t]{2}{*}{ Wavenumber $\left(\mathrm{cm}^{-1}\right)$} & \multirow[t]{2}{*}{ Pre-processing } & \multicolumn{3}{|c|}{ Calibration set } & \multicolumn{4}{|c|}{ Validation set } \\
\hline & & & Factor & $\mathrm{R}^{2}$ & RMSEE & $\mathrm{r}^{2}$ & RMSECV & RPD & Bias \\
\hline GCV $(\mathrm{J} / \mathrm{g})$ & $7502.2-4597.7$ & $1^{\text {st }}$ derivative + MSC & 7 & 0.95 & 354 & 0.90 & 445 & 3.19 & 3.69 \\
\hline $\mathrm{AC}(\% \mathrm{wt})$ & $6102-5446.3$ & Non- preprocessed & 5 & 0.90 & 1.49 & 0.83 & 1.7 & 2.44 & 0.006 \\
\hline
\end{tabular}



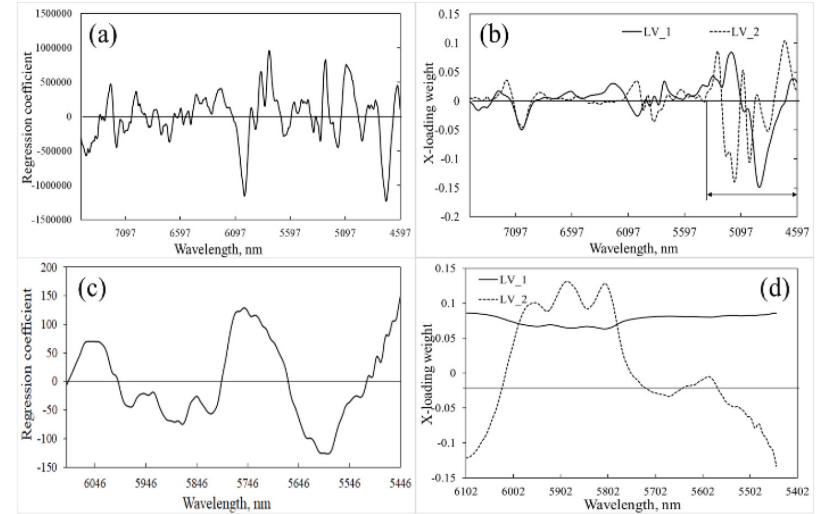

Fig. 4. regression coefficient (a and c) and $X$-loading (b and d) for gross calorific and ash content, respectively. LV_1 and LV_2 are latent variable for factor 1 and 2, respectively.

\subsection{Prediction of unknow samples}

Fig.5 shows the measured value, predicted value, and target line of unknown sample obtained from various area, the total sample was 10. The performance gave the SEP and bias of $671 \mathrm{~J} / \mathrm{g}$ and $-654 \mathrm{~J} / \mathrm{g}$ for $\mathrm{GCV}$ model, respectively, while AC provided SEP and bias of 1.840 $\%$ wt and $0.912 \%$ wt, respectively.
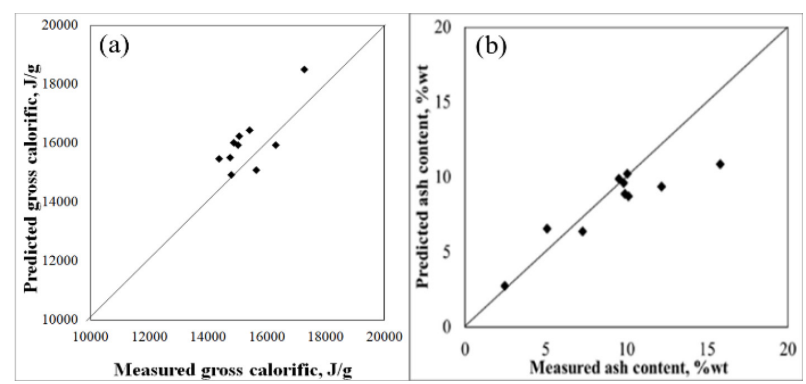

Fig. 5. Measured value versus predicted value of a( gross calorific value and $b$ ( ash content for unknown sample.

\section{Conclusion}

As seen the results, shows that NIR spectroscopy could be used as rapid and non-destructive for quality assurance and the prediction of GCV and AC content of sawdust. The model for GCV and AC gave a superior performance with validated by the full cross validation. To ensure the capacity of calibration model, the unknown sample collected from different sawdust milled plant were used to test. The performance for predicting unknown sample set was acceptable for screening. The meaning was that unknown sample is the representative population for future. This research was useful for qualitative screening the biomass to the thermal conversion plant.

\section{Acknowledgment}

The authors thank the Near Infrared Spectroscopy Research Center for Agricultural Product and Food (www.nirsresearch.com) at King Mongkut's Institute of Technology Ladkrabang, Bangkok, Thailand, for the use of their instruments.

\section{References}

1. B.A. Wani, R.H. Bodha, A.H. Wani, J. Med. Plant Res. 4, 2598-2604, (2010)

2. R. Sanmee, B. Dell, P. Lumyong, K. Izumori, S. Lumyong, Food Chem. 82, 527-532, (2003)

3. A. Kettawan, K. Chanlekha, R. Kongkachuichai, R. Charoensiri, Pak. J. Nutr. 10, 1094-1103, (2011)

4. A. Srikram, S. Supapvanich, ANRES. 50(6), 432436, (2016)

5. M. Thevasingh, W. Pale, W.C. Kyung, Mushroom Growers Handbook 2 Shiitake Cultivation (Mushworld, Seoul, 2005)

6. C. Yongtie, Y. Wenming, Z. Zhimin, X. Mingchen, P. Subbaiah, Energy Procedia 143, 623-628 (2017)

7. A. Monti, N.D. Virgilio, G. Venturi, Biomass Bioenergy 32(3), 216-23, (2008)

8. G.D. Gillespie, C.D. Everard, K.P. McDonnell, Energy 80, 582-588, (2015)

9. K. Zhang, L. Zhou, M. Brady, F. Xu, J. Yu, D. Wang, Energy 118, 1353 - 1360, (2017)

10. J. Posom, A. Shrestha, W. Saechua, P. Sirisomboon, Energy 107, $464-472$, (2016)

11. J. Posom, P. Sirisomboon, Biosyst Eng., 130, 52 - 59. (2015)

12. C. Huang, L. Han, Z. Yang, X. Liu, Energy Convers. Manag. 49, 3433 - 3438, (2008)

13. C.C. Fagan, C.D. Everard, K. McDonnell, Bioresour. Technol. 102(8), 5200-5206, (2011)

14. P. Dardenne, NIR News 21, 8-14, (2010)

15. J. Workman, J.R.L. Weyer, Practical Guide to Interpretive Near-infrared Spectroscopy (Taylor and Francis, Boca Raton, 2007)

16. B.G. Osborne, T. Fearn, Near Infrared Spectroscopy in Food Analysis (Longman Science \& Technical, London, 1986)

17. P. Williams, Near-Infrared Technology Getting the Best Out of Light Edition 5.0. (PDK Grain, Nanaimo, 2007)

18. J.S. Shenk, J.J. Workman, Jr., M.O. Westerhaus. Hand book of Near-Infrared Analysis (CRC press, Taylor \& Francis Group, 2008) 